\author{
Philippe Eggimann \\ Michel Wolff \\ Jorge Garbino
}

\section{Oral nystatin as antifungal prophylaxis in critically ill patients: an old SDD tool to be renewed?}

Received: 17 August 2005

Accepted: 29 August 2005

Published online: 30 September 2005

(C) Springer-Verlag 2005

This editorial refers to the article available at: http://dx.doi.org/ 10.1007/s00134-005-2807-x

\section{P. Eggimann (৫)}

Service des Soins Intensifs de Chirurgie et Centre des Brûlés, Centre Hospitalier Universitaire Vaudois (CHUV),

Lausanne, Switzerland

e-mail: philippe.eggimann@ chuv.ch

\section{Wolff}

Service de Réanimation Médicale et des Maladies infectieuses, Hôpital Bichat-Claude Bernard, AP/HP,

Paris, France

\section{J. Garbino}

Service des Maladies Infectieuses, Département de Médecine Interne, Hôpitaux Universitaires de Genève, Geneva (HUG), Switzerland

Invasive candidiasis remains a dreadful complication in hospitalized patients, generally associated with poor prognosis $[1,2]$. Except in the case of candidemia, it is difficult to diagnose. In contrast to Aspergillus spp., biological tools have not been developed to diagnose candidiasis [3], and using the current clinical and microbiological criteria the threshold between colonization and infection may be difficult to distinguish [4]. Risk factors including colonization predispose to the development of invasive candidiasis in both immunocompromised and nonimmunocompromised patients [5, 6, 7]. However, as a majority of them are directly linked to an underlying disease or its treatments, it is almost impossible to target them for prevention. The high proportion of bone marrow transplant recipients developing candidiasis has stimulated clinical research which has es- tablished the value of antifungal prophylaxis. Azolebased prophylaxis has progressively imposed as a standard of care for severely neutropenic patients [8] and in most solid-organ transplant recipients [9]. However, antifungal prophylaxis has been repeatedly implicated in the increasing proportion of non-albicans Candida isolated in many cancer centers $[10,11]$. This has generated a considerable debate, and guidelines have been modified accordingly [12].

This is not the case in nonimmunocompromised critically ill patients, in whom international surveillance programs have shown that $C$. albicans remains the predominant strain in most countries [13]. Moreover, this is also the case in almost all recent series on candidiasis in ICU patients $[14,15,16,17]$. Several characteristics of these patients may have a strong impact on this ecology. ICU patients present many risk factors for invasive candidiasis. In particular, a high proportion of them become colonized with Candida spp., but only a minority develop invasive candidiasis. However, related to its poor prognosis, the difficulty in identifying subgroups of patients that could benefit from prophylaxis, and to the good security profile of azoles, it may be tempting to treat systematically all colonized patients. According to the experience acquired with immunocompromised patents, this should be avoided.

Colonization by Candida spp. is an independent risk factor for candidiasis. As assessed by the colonization index proposed by Pittet and confirmed by others [14, 15, 16], increasing growth of Candida spp. from multiple body sites is predictive of subsequent invasive candidiasis. Despite several studies in critically ill nonimmunosuppressed patients $[14,15,16,17]$ antifungal prophylaxis has been insufficiently validated and is currently not included in most published guidelines. However, a systematic review and meta-analysis of these studies just published in Intensive Care Medicine Journal shows a significantly reduced rate of candidiasis, overall mortality, and cases attributable to candidiasis [18]. This con- 
firms the proposal of some experts to consider prophylaxis in these patients. All these authors recommend strictly restricting them to high-risk patients $[14,15,16$, 17, 18]. However, such patients are difficult to identify. Identifying them relies on sophisticated and nonvalidated clinical approaches combining the presence of nonspecific risk factors and on the dynamic of colonization by Candida [4].

The study performed by Normand et al. [19] now published in Intensive Care Medicine suggests a novel way in which to prevent invasive candidiasis in critically ill patients. The open-label study randomized 98 patients mechanically ventilated for more than $48 \mathrm{~h}$ to receive oral prophylaxis by nystatin or a placebo. No invasive candidiasis developed, but prophylaxis significantly reduced the colonization index and prevented colonization. The absence of invasive candidiasis was due to the selection of patients at low risk of developing such complication. The severity score at study entry, proportion of patients colonized at entry, and mean value of the colonization index were lower than in other prophylactic studies [14, $15,16,17]$. This confirms that low-risk patients are characterized by a low proportion of colonization and by a persistent low value of the colonization index over time. Moreover, persistently low values of the colonization index strongly suggested that prophylaxis interferes with the dynamic of colonization by Candida spp. in patients receiving nystatin.

Nystatin, as with amphotericin B, is a nonabsorbable polyene with a wide antifungal activity, especially against Candida spp., including C. glabrata and C. krusei. Prophylaxis with nystatin has often been disappointing in immmunocompromised patients, and a meta-analysis found no differences to placebo in colonization or mortality [20]. However, the dose of nystatin and method of administration differed across studies, precluding comparisons of efficacy.

A nonabsorbable drug may present an elegant alternative to the complex and difficult selection of patients at high risk who could benefit from antifungal prophylaxis. The results reported by Normand et al. are the first suggesting a potential efficacy of nystatin prophylaxis in nonimmunocompromised ICU patients. However, it should be remembered that selective decontamination of the digestive tract (SDD) is aimed to prevent nosocomial infection in ICU patients, including those caused by fungi. Nonabsorbable polyenes are integrated in most SDD regimens, and a recent meta-analysis showed that they significantly reduce fungal carriage and overall fungal infections, but without impact on fungemia. However, only few trials were available for analysis of fungal carriage and the definitions of fungal infections were heterogeneous [21].

In critically nonimmunocompromised patients several advantages may favor the use of nystatin instead of azoles as a prophylactic antifungal regimen. First, a nonabsorbable molecule, different from other drugs available for treatment, is an attractive concept. As indicated above, although most species of Candida isolated in ICU patients remain susceptible to azoles, indiscriminate use of such drugs may lead to the spread of C. krusei and C. glabrata, intrinsically resistant and dose-dependent sensitive to azoles, respectively. In contrast, primary resistance to polyenes among Candida spp. is limited to C. lusitaniae and to some strains of $C$. guillermondii, and resistance seldom develops during treatment. Therefore polyene prophylaxis is less likely to promote the emergence of resistant strains of Candida. Second, Normand et al. did not observe adverse effects of nystatin. Azoles are generally well tolerated, but side effects such as hepatic dysfunction are possible. These risks, even if low, could be more difficult to accept in the setting of prophylaxis in critically ill patients. The third advantage of oral nystatin is its low cost, making this strategy potentially highly cost effective-if it works!

Accordingly, as suggested by the authors, these preliminary data should stimulate the medical community to explore the usefulness of oral nystatin prophylaxis in other groups of critically ill patients at higher risk. If confirmed, such approach may contribute to solve ongoing controversies in the field of prevention of invasive candidiasis in nonimmunocompromised critically ill patients.

\section{References}

1. Wey SB, Mori M, Pfaller MA, Woolson RF, Wenzel RP (1988) Hospital-acquired candidemia. The attributable mortality and excess length of stay. Arch Intern Med 148:2642-2645
2. Mora-Duarte J, Betts R, Rotstein C, Colombo AL, Thompson-Moya L, Smietana J, Lupinacci R, Sablen C, Kartsonis N, Perfect J for the Caspofungin Invasive Candidiasis Study Group (2002) Comparison of caspofungin and amphotericin B for invasive candidiasis. N Engl J Med 347:20202029
3. Prella M, Bille J, Pugnale M, Duvoisin B, Cavassini M, Calandra T, Marchetti O (2005) Early diagnosis of invasive candidiasis with mannan antigenemia and antimannan antibodies. Diagn Microbiol Infect Dis 51:95-101

4. Eggimann P, Garbino J, Pittet D (2003) Epidemiology of Candida species infections in critically-ill non-immunosuppressed patients. Lancet Infect Dis 3:685-702 
5. Wey SB, Mori M, Pfaller MA, Woolson RF, Wenzel RP (1989) Risk factors for hospital-acquired candidemia. Arch Intern Med 149:2349-2353

6. Calandra T, Bille J, Schneider R, Mosimann F, Francioli P (1989) Clinical significance of Candida isolated from peritoneum in surgical patients Lancet II: $1437-440$

7. Blumberg HM, Jarvis WR, Soucie JM, Edwards JE, Patterson JE, Pfaller MA, Rangel-Frausto MS, Rinaldi MG, Saiman L, Wiblin RT, Wenzel RP, National Epidemiology of Mycoses Survey (NEMIS) Study Group (2001) Risk factors for candidal bloodstream infections in surgical intensive care unit patients: the NEMIS prospective multicenter study. The National Epidemiology of Mycosis Survey. Clin Infect Dis 33:177-186

8. Bow EJ, Laverdiere M, Lussier N, Totstein C, Cheang MS, Ioannou S (2002) Antifungal prophylaxis for severely neutropenic chemotherapy recipients: a meta analysis of randomizedcontrolled clinical trials. Cancer 94:3230-3246

9. Pappas PG, Rex JH, Sobel JD, Filler SG, Dismukes WE, Walsh TJ, Edwards JE (2004) Guidelines for treatment of candidiasis Clin Infect Dis 38:161-189

10. Anaissie EJ, Rex JH, Uzun O, Vartivarian S (1998) Predictors of adverse outcome in cancer patients with candidemia. Am J Med 104:238-245
11. Viscoli C, Girmenia C, Marinus A, Collette L, Martino P, Vandercam B, Doyen C, Lebeau B, Spence D, Krcmery V, De Pauw B, Meunier F (1999) Candidemia in cancer patients: a prospective, multicenter surveillance study by the Invasive Fungal Infection Group (IFIG) of the European Organization for Research and Treatment of Cancer (EORTC). Clin Infect Dis 28:1071-1079

12. Hughes WT, Armstrong D, Bodey GP, Bow EJ, Brown AE, Calandra T, Feld R, Pizzo PA,Rolston KV, Shenep JL, Young LS (2002) 2002 guidelines for the use of antimicrobial agents in neutropenic patients with cancer. Clin Infect Dis 34:730-751

13. Pfaller MA, Diekema DJ, Jones RN, Messer SA, Hollis RJ, SENTRY participant groups (2002) Trends in antifungal susceptibility of Candida spp. isolated from pediatric and adult patients with bloodstream infections: SENTRY Antimicrobial Surveillance Program, 1997 to 2000. J Clin Microbiol 40:852-856

14. Garbino J, Lew PD, Romand JA, Hugonnet S, Auckenthaler R, Pittet D (2002) Prevention of severe Candida infections in non-neutropenic, highrisk, critically ill patients. A randomized, double-blind, placebo-controlled trial in SDD-treated patients. Intensive Care Med 28:1708-1717

15. Dupont H, Bourichon A, Paugam-Burtz C, Mantz J, Desmonts JM (2003) Can yeast isolation in peritoneal fluid be predicted in intensive care unit patients with peritonitis? Crit Care Med 31:752757
16. Piarroux R, Grenouillet F, Balvay $P$, Tran V, Blasco G, Milloin L, Boillot A (2004) Assessment of preemptive treatment to prevent severe candidiasis in critically-ill surgical patients. Crit Care Med 32:2443-2449

17. Eggimann P, Francioli P, Bille J, Schneider R, WU MM, Chapuis G, Chiolero R, Pannatier A, Schilling J, Geroulanos S, Glauser MP, Calandra T (1999) Fluconazole prophylaxis prevents intra-abdominal candidiasis in high-risk surgical patients. Crit Care Med 27:1066-1072

18. Cruciani M, de Lalla F, Mengoli C (2005) Prophylaxis of Candida infections in adult trauma and surgical intensive care patients: a systematic review and meta-analysis. Intensive Care Med ( 10.1007/s00134-005-2794-y)

19. Normand S, François B, Dardé ML, Bouteille B, Bonnivard M, Preux PM, Gastinne H, Vignon P (2005) Oral nystatin prophylaxis of Candida spp. Colonization in ventilated critically-ill patients. Intensive Care Med (DOI: 10.1007/s00134-005-2807-x)

20. Gotzsche PC, Johansen HK (2002). Nystatin prophylaxis and treatment in severely immunodepressed patients. Cochrane Database Syst Rev

21. Silvestri L, van Saene HK, Milanese M, Gregori D (2005) Impact of selective decontamination of the digestive tract on fungal carriage and infection: systematic review of randomized controlled trials. Intensive Care Med 31:898-910 